\title{
Hipotiroidismo y falla renal: reporte de caso y revisión de la literatura
}

\author{
Patricia Reyes R. $M D^{1}$, Andrés Flórez R. $M D^{2}$, Alejandra Rivera B. $M D^{3}$
}

${ }^{1}$ Médica Internista Endocrinóloga, Fundación Universitaria de Ciencias de la Salud, Bogotá DC. Colombia.

${ }^{2}$ Médico Internista. Residente endocrinología, Fundación Universitaria de Ciencias de la Salud, Bogotá DC. Colombia. ${ }^{3}$ Médica Internista. Residente endocrinología, Fundación Universitaria de Ciencias de la Salud, Bogotá DC. Colombia.

Fecha de recepción: 22/06/2017

Fecha de aceptación: 30/07/2017

\section{Resumen}

$\mathrm{E}$ l hipotiroidismo es una enfermedad común en la práctica diaria, estados severos pueden afectar cualquier órgano, incluso el riñón. Presentamos el caso de un paciente masculino de 35 años, con un cuadro clínico consistente en edema palpebral y de miembros inferiores, astenia y adinamia, quien consultó al servicio de urgencias, donde se documentó creatinina en $2,1 \mathrm{mg} / \mathrm{dl}$, parcial de orina normal, no uso de nefrotóxicos, ni antecedentes de importancia. Se solicitaron estudios, descartando diabetes, hiperuricemia, enfermedades autoinmunes o alteraciones estructurales. Por sintomatología referida por el paciente, se solicitó TSH en $1.200 \mu \mathrm{U} / \mathrm{mL}$. Se consideró nefropatía secundaria a hipotiroidismo y se inició suplencia hormonal. Se confirmó autoinmunidad tiroidea, seguimiento con disminución progresiva de la creatinina $(1,23 \mathrm{mg} / \mathrm{dl})$ y la TSH $(2 \mu \mathrm{U} / \mathrm{mL})$.

Conclusiones: Los cambios renales en el hipotiroidismo son secundarios a compromiso directo a nivel glomerular (disminución de la expresión de vasodilatadores renales y formación de inmunocomplejos) y tubular (reducción acción $\mathrm{Na}+/ \mathrm{K}+$ ATPasa, intercambiador $\mathrm{Na}+\mathrm{H}+\mathrm{y}$ aumento en la reabsorción de agua). $\mathrm{Y}$ efectos indirectos asociados a los cambios hemodinámicos; Aumento de la resistencia vascular periférica y disminución del gasto cardiaco. Nuestro paciente es un reflejo del compromiso de la tasa de filtración glomerular (TFG) en el hipotiroidismo severo y la reversión de la disfunción renal con el tratamiento.

Palabras clave: Tiroides, riñón, hipotiroidismo, enfermedad renal crónica.

\section{Introducción}

El hipotiroidismo es una patología frecuente en la práctica diaria que, en estados severos, puede comprometer la función de múltiples órganos. El riñón, desde la embriogénesis, está influenciado por los niveles de hormonas tiroideas que, tanto en el hipertiroidismo como en el hipotiroidismo, afectan la función glomerular y tubular, por efectos directos o indirectos. Presentamos el caso de un paciente de género masculino que debutó con síntomas de hipotiroidismo y creatinina elevada, con TSH en $1200 \mu \mathrm{U} / \mathrm{mL}^{(1)}$, en quien se descartaron otras causas de nefropatía, y se observa mejoría de la función renal con la suplencia hormonal. Al final del artículo se realiza una revisión del tema en relación con las alteraciones renales asociadas a hipotiroidismo.

\section{Caso clínico}

Paciente de sexo masculino de 35 años, con cuadro clínico de varios días de evolución consistente en edema palpebral y de miembros inferiores, astenia, adinamia, estreñimiento e incremento progresivo del peso. Al examen físico IMC 27 con fascies abotagadas y bocio grado 2 . Consulta a urgencias, en donde encuentran creatinina en $2 \mathrm{mg} / \mathrm{dl}$ y parcial de orina normal, con densidad urinaria y pH normales; niega uso de nefrotóxicos, sin infecciones recientes, no antecedente de hipertensión arterial, ni otros antecedentes de importancia. Es valorado por nefrología y se solicitan estudios; ácido úrico normal, glucemia y hemoglobina glucosilada normales, microalbuminuria/creatinuria normal, ANAS negativos, ecografía renal y vías urinarias sin alteraciones en parénquima renal, ni patología prostática. Por sintomatología referida, se solicita TSH, que se encuentra en $1.200 \mu \mathrm{U} / \mathrm{mL}$ (resultado reconfirmado en laboratorio); se considera nefropatía secundaria a hipotiroidismo; se solicita concepto de endocrinología e inicia levotiroxina $125 \mu \mathrm{g} /$ día $(1,4 \mu \mathrm{g} / \mathrm{kg})$. Es valorado por nuestro servicio dos meses después de iniciar el tratamiento con TSH en $191 \mu \mathrm{U} / \mathrm{mL}$, creatinina en $1,6 \mathrm{mg} / \mathrm{dl}$, colesterol total $383 \mathrm{mg} / \mathrm{dl}$, HDL $40 \mathrm{mg} / \mathrm{dl}$, LDL $209 \mathrm{mg} / \mathrm{dl}$, sodio $138 \mathrm{meq} / \mathrm{L}$ y mejoría de la sintomatología. Se aumenta dosis de levotiroxina a $175 \mu \mathrm{g} /$ día, y continúa simvastatina más ezetimibe indicada por medicina interna, trae anticuerpos antitiroglobulina en $4.000 \mathrm{UI} / \mathrm{mL}$ y ecografía de tiroides con bocio difuso. En último control por nuestro servicio 
presenta TSH $2 \mu \mathrm{U} / \mathrm{mL}$, T4L 1,5 ng/dL, creatinina 1,23 mg/dl, CT $191 \mathrm{mg} / \mathrm{dl}$, HDL $39 \mathrm{mg} / \mathrm{dl}$, LDL $130 \mathrm{mg} / \mathrm{dl}$. En la figura 1, se puede evaluar la evolución de la creatinina y la TSH.

Figura 1. Evolución de la creatinina y la TSH

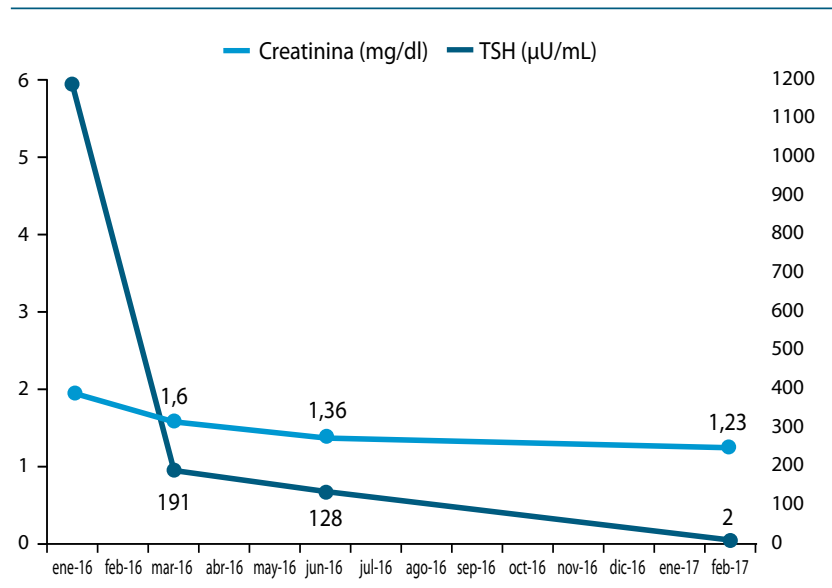

\section{Discusión}

El hipotiroidismo es una entidad frecuente en nuestra población, con un espectro clínico muy amplio que va desde síntomas generales hasta compromiso de órganos como el riñón. Según la publicación de Gopinath y colaboradores, el aumento de la TSH en adultos mayores se ha asociado con mayor riesgo de desarrollar enfermedad renal crónica, independientemente de la edad y la comorbilidades como diabetes e hipertensión arterial $^{(2,3)}$.

Las hormonas tiroideas influyen en el desarrollo del riñón y son fundamentales para la hemodinamia renal, el TFG y la homeostasis de sodio y agua ${ }^{(4)}$. Los trastornos tiroideos, tanto el hipotiroidismo como el hipertiroidismo, afectan la función renal a través de efectos directos e indirectos, asociados a alteraciones hemodinámicas, metabólicas y cardiovasculares generadas por estas enfermedades. Estas alteraciones renales pueden ser reversibles con el tratamiento adecuado(5). En la presente revisión nos centraremos en las alteraciones renales asociadas al hipotiroidismo.

\section{Mecanismos generales de afectación renal en el hipotiroidismo}

En el hipotiroidismo hay disminución en el número de células y tamaño renal, generada por disminución en la síntesis de proteínas y el desarrollo celular, afectando la estructura tubular y glomerular ${ }^{(1,4)}$. Alteraciones hemodinámicas, llevan a disminución de la TFG por vasoconstricción preglomerular, lo que genera disminución del flujo sanguíneo renal y predisposición a lesión renal de origen prerrenal ${ }^{(5)}$. Se ha observado reducción en la expresión de vasodilatadores renales (el factor de crecimiento endotelial vascular y el factor de crecimiento similar a la insulina); disminución de las moléculas que inhi- ben la calcificación vascular (proteína Gla de la matriz); y aumento en el contenido de calcio(6).

La cistatina $\mathrm{C}$ es un inhibidor de la proteinasa de la cisteína, que se produce constantemente por la mayoría de células nucleadas y se filtra libremente en el glomérulo, para luego ser reabsorbida y metabolizada por las células epiteliales del túbulo proximal. Sus niveles se disminuyen en pacientes con hipotiroidismo, teniendo un comportamiento opuesto a la creatinina ${ }^{(7,8)}$. La elevación de la creatinina sérica puede ocurrir en el 55\% de los pacientes en las primeras dos semanas de inicio del hipotiroidismo y los niveles se normalizan rápidamente después de la terapia con levotiroxina ${ }^{(9)}$; es secundaria a la disminución de la TFG y la generación por catabolismo de proteínas musculares ${ }^{(4)}$. Tratar el hipotiroidismo subclínico mejora la TFG y retrasa la progresión a enfermedad renal terminal ${ }^{(7)}$.

La TFG se encuentra reducida en el $40 \%$ de los pacientes con hipotiroidismo. Los mecanismos involucrados son ${ }^{(4,10)}$ :

- Disminución del gasto cardiaco, volumen circulante, disminución del eje renina-angiotensina-aldosterona y disminución del péptido natriurético auricular.

- Disminución de la cantidad de glomérulos.

- Vasoconstricción preglomerular.

- Disminución canales de cloro CIC-2, disminuyendo la TFG cuando hay incremento en la carga de cloro.

\section{Hipotiroidismo y compromiso tubular renal}

A nivel tubular, los efectos se presentan a largo plazo. Se reduce la acción de la bomba $\mathrm{Na}+\mathrm{K}+\mathrm{ATPasa}^{(4,7,11)}$. El intercambiador $\mathrm{Na}+\mathrm{H}+$ está disminuido ${ }^{(12)}$, provocando pérdida de sodio y bicarbonato en la orina, alterando la acidificación urinaria y la concentración urinaria. Hay aumento en la reabsorción de agua mediada por aumento en la transcripción de acuaporina 1 en el túbulo proximal ${ }^{(13)}$, liberación no osmótica de vasopresina y transcripción de acuaporina $2^{(14)}$.

El trastorno hidroelectrolítico más común encontrado en pacientes con hipotiroidismo es la hiponatremia, la cual está presente en el $45 \%$ de los pacientes con creatinina elevada y en el $21 \%$ de los que tienen creatinina normal. Esto se debe a la reducción de la $\mathrm{TFG}^{(7)}$, la disminución de la actividad de la bomba $\mathrm{Na}+/ \mathrm{K}+$ ATPasa y el intercambiador $\mathrm{Na}+\mathrm{H}+$ y el aumento en la reabsorción de agua.

\section{Hipotiroidismo y compromiso glomerular}

Lesiones glomerulares tales como engrosamiento de la membrana basal e incremento de la matriz mesangial pueden ser secundarias a disminución del flujo sanguíneo renal, por los mecanismos ya mencionados ${ }^{(4)}$. Así mismo, hay disminución de los glomérulos, dado que la hormona tiroidea es importante para el desarrollo celular.

La enfermedad tiroidea autoinmune puede generar inmunocomplejos en un $50 \%$ de los pacientes y puede estar asociada con aparición de glomerulonefritis mediada por depósito 
en la membrana basal de los glomérulos ${ }^{(15)}$. Se ha descrito proteinuria leve en el 29,8\% de los pacientes con tiroititis autoinmune. Sin embargo, la etiología no es del todo conocida; incluso, varias enfermedades glomerulares como la vasculitis o la nefritis lúpica, pueden estar acompañadas de enfermedad tiroidea autoinmune ${ }^{(1)}$. Las enfermedades glomerulares inmunomediadas asociadas a hipotiroidismo, se encuentran en la tabla 1.

Tabla 1. Enfermedades glomerulares inmunomediadas asociadas a hipotiroidismo

\begin{tabular}{l}
\hline Nefropatía membranosa \\
\hline Glomerulonefritis por lgA \\
\hline Glomerulonefritis membranoproliferativa \\
\hline Enfermedad de cambios mínimos \\
\hline
\end{tabular}

\section{Hipotiroidismo y cambios hemodinámicos con impacto renal}

Los cambios hemodinámicos encontrados en el hipotiroidismo están relacionados con diferentes componentes del sistema cardiovascular, que llevan a alteración de la contractilidad cardiaca, consumo de oxígeno miocárdico, resistencia vascular periférica, conducción eléctrica y presión arterial ${ }^{(4)}$. Los cambios a nivel cardiaco son dados por alteraciones en la trascripción de genes en el miocito, que afectan la contractilidad con compromiso de la función sistólica, y trastornos diastólicos de la relajación, afectando de este modo el gasto cardiaco ${ }^{(16)}$. Como ya se ha mencionado, hay disminución de la síntesis de vasodilatadores, endoteliales llevando a un aumento de la resistencia vascular sistémica y un aumento de la tensión arterial diastólica ${ }^{(1)}$.

El hipotiroidismo se asocia con disminución de la sensibilidad al estímulo betadrenérgico ${ }^{(17)}$, disminución de la expresión génica de renina, disminución de la síntesis de angiotensina y receptores de angiotensinógeno; es decir, hay disminución de la actividad del sistema renina-angiotensina-aldosterona ${ }^{(4,16,18)}$. Otros hallazgos tienen que ver con la disminución del factor natriurético auricular y baja producción de eritropoyetina ${ }^{(19)}$.

En la tabla 2, se registra un resumen de los efectos renales del hipotiroidismo.

Tabla 2. Efectos renales del hipotiroidismo

\begin{tabular}{l|l|l}
\multicolumn{1}{c|}{$\begin{array}{c}\text { Cambios } \\
\text { glomerulares }\end{array}$} & \multicolumn{1}{c|}{$\begin{array}{c}\text { Cambios } \\
\text { tubulares }\end{array}$} & \multicolumn{1}{c}{$\begin{array}{c}\text { Cambios } \\
\text { hemodinámicos }\end{array}$} \\
$\begin{array}{l}\text { Disminución de la } \\
\text { tasa de filtración } \\
\text { glomerular }\end{array}$ & $\begin{array}{l}\text { Disminución de } \\
\text { la actividad } \mathrm{Na+/} \\
\text { K+ ATPasa y del } \\
\text { intercambiador Na+/ } \\
\text { H+ }\end{array}$ & $\begin{array}{l}\text { Disminución de } \\
\text { la sensibilidad } \\
\text { de estímulo beta } \\
\text { adrenérgico }\end{array}$ \\
\hline $\begin{array}{l}\text { Disminución de } \\
\text { la expresión de } \\
\text { vasodilatadores } \\
\text { renales }\end{array}$ & $\begin{array}{l}\text { Aumento de la } \\
\text { producción de } \\
\text { vasopresina }\end{array}$ & $\begin{array}{l}\text { Disminución de la } \\
\text { actividad del sistema } \\
\text { renina-angiotensina- } \\
\text { aldosterona }\end{array}$ \\
\hline $\begin{array}{l}\text { Aumento de la } \\
\text { expresión de la } \\
\text { proteína de la matriz } \\
\text { Gla }\end{array}$ & $\begin{array}{l}\text { Aumento de la } \\
\text { expresión de } \\
\text { acuaporina 1 y 2 }\end{array}$ & $\begin{array}{l}\text { Aumento de la } \\
\text { tensión arterial } \\
\text { media }\end{array}$ \\
\hline $\begin{array}{l}\text { Aumento de la } \\
\text { creatinina sérica }\end{array}$ & & $\begin{array}{l}\text { Disminución de } \\
\text { la producción de } \\
\text { eritropoyetina }\end{array}$ \\
\hline $\begin{array}{l}\text { Disminución de } \\
\text { niveles de cistatina C }\end{array}$ & $\begin{array}{l}\text { Disminución de los } \\
\text { niveles de péptido } \\
\text { natriurético auricular }\end{array}$ \\
\hline $\begin{array}{l}\text { Aumento de la } \\
\text { permeabilidad } \\
\text { capilar glomerular }\end{array}$ & & \\
\hline
\end{tabular}

\section{Referencias}

1. Dousdampanis P, Trigka K, Vagenakis GA, Fourtounas C. The thyroid and the kidney: a complex interplay in health and disease. Int J Artif Organs. 2014;37(1):1-12.

2. Den Hollander JG, Wulkan RW, Mantel MJ, Berghout A. Correlation between severity of thyroid dysfunction and renal function. Clin Endocrinol (Oxf). 2005;62(4):423-7.

3. Gopinath B, Harris DC, Wall JR, Kifley A, Mitchell P. Relationship between thyroid dysfunction and chronic kidney disease in community-dwelling older adults. Maturitas. 2013;75(2):159-64.

4. Van Hoek I, Daminet S. Interactions between thyroid and kidney function in pathological conditions of these organ systems: a review. Gen Comp Endocrinol. 2009;160(3):205-15.

5. Iglesias P, Bajo MA, Selgas R, Díez JJ. Thyroid dysfunction and kidney disease: An update. Rev Endocr Metab Disord. 2016.

6. Sato Y, Nakamura R, Satoh M, Fujishita K, Mori S, Ishida S, et al. Thyroid hormone targets matrix Gla protein gene associated with vascular smooth muscle calcification. Circ Res. 2005;97(6):550-7.

7. Iglesias P, Díez JJ. Thyroid dysfunction and kidney disease. Eur J Endocrinol. 2009;160(4):503-15.

8. Ye Y, Gai X, Xie H, Jiao L, Zhang S. Impact of thyroid function on serum cystatin $\mathrm{C}$ and estimated glomerular filtration rate: a cross-sectional study. Endocr Pract. 2013;19(3):397-403.

9. Montenegro J, González O, Saracho R, Aguirre R, Martínez I. Changes in renal function in primary hypothyroidism. Am J Kidney Dis. 1996;27(2):195-8.

10. Basu G, Mohapatra A. Interactions between thyroid disorders and kidney disease. Indian J Endocrinol Metab. 2012;16(2):204-13.
11. Ohara T, Ikeda U, Muto S, Oguchi A, Tsuruya Y, Yamamoto K, et al. Thyroid hormone stimulates $\mathrm{Na}(+)-\mathrm{K}(+)$-ATPase gene expression in cultured rat mesangial cells. Am J Physiol. 1993;265(3 Pt 2):F370-6.

12. Li X, Misik AJ, Rieder CV, Solaro RJ, Lowen A, Fliegel L. Thyroid hormone receptor alpha 1 regulates expression of the $\mathrm{Na}+\mathrm{H}+$ exchanger (NHE1). J Biol Chem. 2002;277(32):28656-62.

13. Nielsen S, Agre P. The aquaporin family of water channels in kidney. Kidney Int. 1995;48(4):1057-68.

14. Chen YC, Cadnapaphornchai MA, Yang J, Summer SN, Falk S, Li C, et al. Nonosmotic release of vasopressin and renal aquaporins in impaired urinary dilution in hypothyroidism. Am J Physiol Renal Physiol. 2005;289(4):F672-8.

15. Calder EA, Penhale WJ, Barnes EW, Irvine WJ. Evidence for circulating immune complexes in thyroid disease. Br Med J. 1974;2(5909):30-1.

16. Cini G, Carpi A, Mechanick J, Cini L, Camici M, Galetta F, et al. Thyroid hormones and the cardiovascular system: pathophysiology and interventions. Biomed Pharmacother. 2009;63(10):742-53.

17. Pracyk JB, Slotkin TA. Thyroid hormone differentially regulates development of beta-adrenergic receptors, adenylate cyclase and ornithine decarboxylase in rat heart and kidney. J Dev Physiol. 1991;16(4):251-61.

18. Vargas F, Rodríguez-Gómez I, Vargas-Tendero P, Jimenez E, Montiel M. The renin-angiotensin system in thyroid disorders and its role in cardiovascular and renal manifestations. J Endocrinol. 2012;213(1):25-36.

19. Mariani LH, Berns JS. The renal manifestations of thyroid disease. J Am Soc Nephrol. 2012;23(1):22-6. 